\title{
REVISTAMATĒRIA
}

ISSN 1517-7076 artigo e-12073, 2018

\section{Analysis of biodeterioration wood estate: use different techniques to obtain images}

Paula Vanesa Alfieri ${ }^{1}$, María Verónica Correa ${ }^{1}$

${ }^{1}$ L.E.M.I.T.: Laboratorio de Entrenamiento Multidisciplinario para la Investigación Tecnológica. Comisión de Investigaciones Científicas de la Provincia de Buenos Aires. La Plata, Buenos Aires, Argentina, Tel/Fax: +54-0221-483-1141/44 e- mail: mavecorrea@ hotmail.com; paulaalferi@gmail.com

\section{ABSTRACT}

This study was based on the current status of locomotive turntable of Provincial Railway Station in La Plata. It was inaugurated in 1910 and it was declared as architectural heritage in 2006. The locomotive turntable is 200 meters from this station and it is a structure that consists in wooden slats of Schinopsis sp. into metal framework. Currently, this structure shows an advanced status of degradation caused by environmental and biological factors.

The objective of this work was to determine the wood fungal degradation by non-destructive methods: area occupied by fungus (mycelium and basidiomata) were observed by X-ray radiography (XR) and Computer tomography (TC) and quantified by image analysis with Image J software. To establish the microstructural degradation (cell wall), ultrathin cut were analyzed by scanning electron microscopy (SEM).

The radiographic images were analyzed by Image J and allowed to determinate that the affected area by wood decay fungus inside wood was higher than outside (superficial view). This confirms that external degradation did not correlate with the internal status. TC images showed internal wood structure loss, which were correlated with the presence of fungal hyphae along the entire slat.

Finally, wood microstructure was analyzed by SEM, in these images could be observed the advanced deterioration status of the wood structure, where there are high fungal colonization (hyphae) and wood microstructure loss (the cell wall was degraded).

This deterioration analysis allows an indirect measurement of the structural condition of the material without destroying it. It was concluded that degradation analysis by images is a non-destructive alternative, and validated methodology to determine material status. This is essential in heritage conservation because it allows defining correctly the degradation status that is useful to planning a conservation strategy, avoiding the asset loss.

Keywords: wood, heritage, deteriorated status, non-destructive method, images analysis.

\section{INTRODUCTION}

Wooden cultural heritage is exposed to numerous stress factors: mechanical wear, impact of fluids and solids (erosion); mechanical long-term load and subsequent effects herein, such as creeping or relaxation under tension; stresses induced by moisture changes, (e.g. veneered furniture, plywood elements, structural wood, wooden floor); effect typically occurring under low relative humidity conditions $(<20 \% \mathrm{RH})$ for example during winter-time in heated rooms. Insect attack or fungal decay occurring for wood moisture contents more than $20 \%$ and those are a typical problem in building and civil engineering, and obviously wooden cultured heritage is affected too. Generally, it can be assumed that wood properties scarcely change under dry conditions; only a certain reduction in the variation of the equilibrium moisture content occurs due to the reduction of residual stresses [1].

The totality of the properties of a material which controls its capability of being colonised by one or more groups of living organisms is called the bioreceptivity. Wood colonisation can lead to modification of microstructure and humidity. The roughness of the surface of the material is increased, leading to more favourable conditions for attachment and growth [2]. The biodeterioration of wooden structures is well recognised and has been studied for many years; major organisms involved are xylophages fungi, with their 
wide range of cellulolytic and ligninolytic enzymes, but bacteria can also cause degradation of cellulose [3]. Those microorganisms are specialized in producing hydrolytic enzymes, necessary for the degradation of cellulose, hemicelluloses and lignin [4-5]. The production of extracellular enzymes and the extraction of aggressive metabolic products increase the loss of material [6]. Enzymatic activity (due to cellulases, glucanases, laccases, phenolases) plays an important role in the decay of materials, moreover, if this wood heritage are exposed to high humidity, high temperature, and insufficient air circulation, fungal colonization is more dangerous [7]. Therefore, for the conservation of wood heritage, monitoring and evaluation of structural conditions is necessary and should be an integral part of the routine inspection of the material [8]. When it comes to patrimonial assets, standardized tests, which define the properties of the material reliably, are unfortunately destructive and not applicable in these cases. For these reasons is that the use of nondestructive methods is more appropriate for the initial diagnosis because the historically valuable material will not be damaged by measurement and will provide sufficiently precise information on the quality of the material at this time [9-10].

This study was based on the current deteriorated status of wood slats from locomotive turntable of Provincial Railway Station La Plata [11]. It was declared as architectural heritage in 2006 and it is inaugurated on April 27, 1910. The central station building was designed by the engineer Enrique Dengremont. It presents French features with an eclectic style (142,000 m2), Figure 1. The locomotive turntable is 200 meters from this station $\left(34^{\circ} 56^{\prime} 16^{\prime \prime} \mathrm{S}\right.$ and $57^{\circ} 56^{\prime} 13^{\prime \prime} \mathrm{W}$ ) [12] and it is a structure that consists in wooden slats into metal framework. Currently, this structure is in an advanced state of deterioration caused by environmental and biological factors, as show in Figure 1, panel D. The aim of this work was to determine the level of deteriorated status of wood slats from locomotive turntable of Provincial Railway Station La Plata by non-destructive methods.

\section{MATERIALS AND METHODS}

Four wood slats from locomotive turntable of 120 x 14 × $3.5 \mathrm{~cm}$ were analyzed by non-destructive methods: area occupied by mycelium and basidiomata were observed by X-ray radiography and Computer tomography (CT) and quantified by image analysis with ImageJ software. Grey scales of the images obtained indicated density changes, being a black scale the less dense and white scale the densest.

The X-ray was performed by the Philips Digital Diagnost VM with spinograph and developed with Agfa CR 35 digitizer. As for the tomography was performed with a multi-cut computed tomography of 64 channels Philips Brand, carrying out the same technique that is used in human medicine. The Multiple Detector Tomography is a study that uses X-rays and allows studying the whole body in its entirety in approximately 10 seconds, obtaining an average of 1000 images. The advent of multi-detector tomography provides the possibility to reconstruct images in different planes and in 3D.

To establish the microstructure wood deterioration (cell wall), scanning electron and optical microscopy (SEM and OM) images of ultra-thin sections were analyzed. For OM, was used Microscope DM1000 from Leica. For SEM, was used, Microscope Quanta 200 from FEI.

To identify the biological agent causing deterioration, the basidiomata found both on surface and inside wood slats were isolated and cultured. Determination of the fungus and its in-vitro cultural features were based on IACONIS and WRIGHT [13] and ROBLEDO and URCELAY [14].

\section{RESULTS}

\subsection{Wood identification}

Wood specie of the slats was determined by conventional methods being Schinopsis sp. (Quebracho colorado) which has a density of $1340 \mathrm{~g} / \mathrm{cm}^{3}$, brown to reddish wood and classified as hard according to TORTORELLI [15]. In Argentina, the timbers of Schinopsis spp. are widely utilized because of their hardness and high durability, which are associated with high tannin contents. The most common uses are: fence posts, telegraph poles, bridges, railways, as well as tannin extraction and fire-wood [16].

\subsection{Non-destructive methods}

To determine affected area by wood decay fungus, radiographic images (RX) were analyzed by ImageJ: the mycelium area was $84.6 \%$, while the basidiomata occupies $12 \%$ of the total wood area, figure 2 Panel A. To substantiate this, Computer Tomography scan (CT) was performed, figure 2 Panel B and E. CT images showed the wood structure loss (dark plates in the images, Figure 2), which were correlated with the presence 
of fungal hyphae along the entire slate. In Panel $\mathrm{C}$ shows a photograph of slat from where the TC and RX were performed. In Panel D shows a detail of fungal basidiomata development over the slat.

Those results confirmed that the external view did not correlate with the internal situation: The development of the mycelium was responsible for the deterioration that affects the structural behaviour of the wood due to the degradation of its components. Therefore, by losing material due to the degradation caused by the fungus, the structural commitment becomes intensive and sustained.

\subsection{Wood degradation microstructure}

In order to evaluate the microstructure of the affected wood, ultra-thin sections of the material were analyzed and observed through SEM and OM, Figure 3. These results showed the advanced deterioration of the wood structure, where there is an advanced colonization of fungi (hyphae, panels A and B) and loss of microstructure of wood (degraded cell wall, panels $\mathrm{C}$ and D). It is important to emphasize that the biodeterioration was not proportional to what was observed with the naked eye, so it is necessary to carry out an exhaustive evaluation to guarantee the service of the structures and to avoid losses of the heritage as happened in the case studied here. The present observations allowed concluding that the main agent of deterioration, that produced loss of density of wood and loss of mechanical properties, was the xylophagous fungus found in the slats. It is then necessary to identify and characterize it. For this purpose, macro and microscopic observations were made to determine that the specimens found in the wood slats belong to the family Hymenochaetaceae, Figure 4, Panel B.

\subsection{Wood decay fungi identification}

Subsequent to the identification of the fungus, cultures were carried out in the presence of tannic and gallic acid in order to evaluate the ability of the fungi to secrete oxidative enzymes. The obtained results showed that the cultivated mycelia had oxidative capacity classifying them as very strong according to the method of NOBLES [17]. Therefore, the fungi found might be able to deteriorate this hardwood, Figure 4, Panel A.

The most descriptive characteristics at the morphological level were their effuse-reflex basidioma, whitish mycelium, yellowish brown spores of smooth wall and apiculated. It was also observed the two degradation patterns characteristic of white rot provoked by Phellinus chaquensis (selective and simultaneous), evidenced by the selective delimited areas dispersed in several areas. The appearance of areas with select delineated wood interspersed between areas of rotting wood simultaneously with abundant hyphae mass corresponds to the mottled or nuanced pattern described by BLANCHETTE [18]. The selective lignification was evidenced by the separation of the fibers caused by the degradation of the middle lamella showing colonization of the hyphae through the vessels and the rays of the parenchyma remained unchanged [19]. Generalized cell wall erosion is evidenced by the presence of holes in all cell types, Figure 3, Panels B, $\mathrm{C}$, and D. 


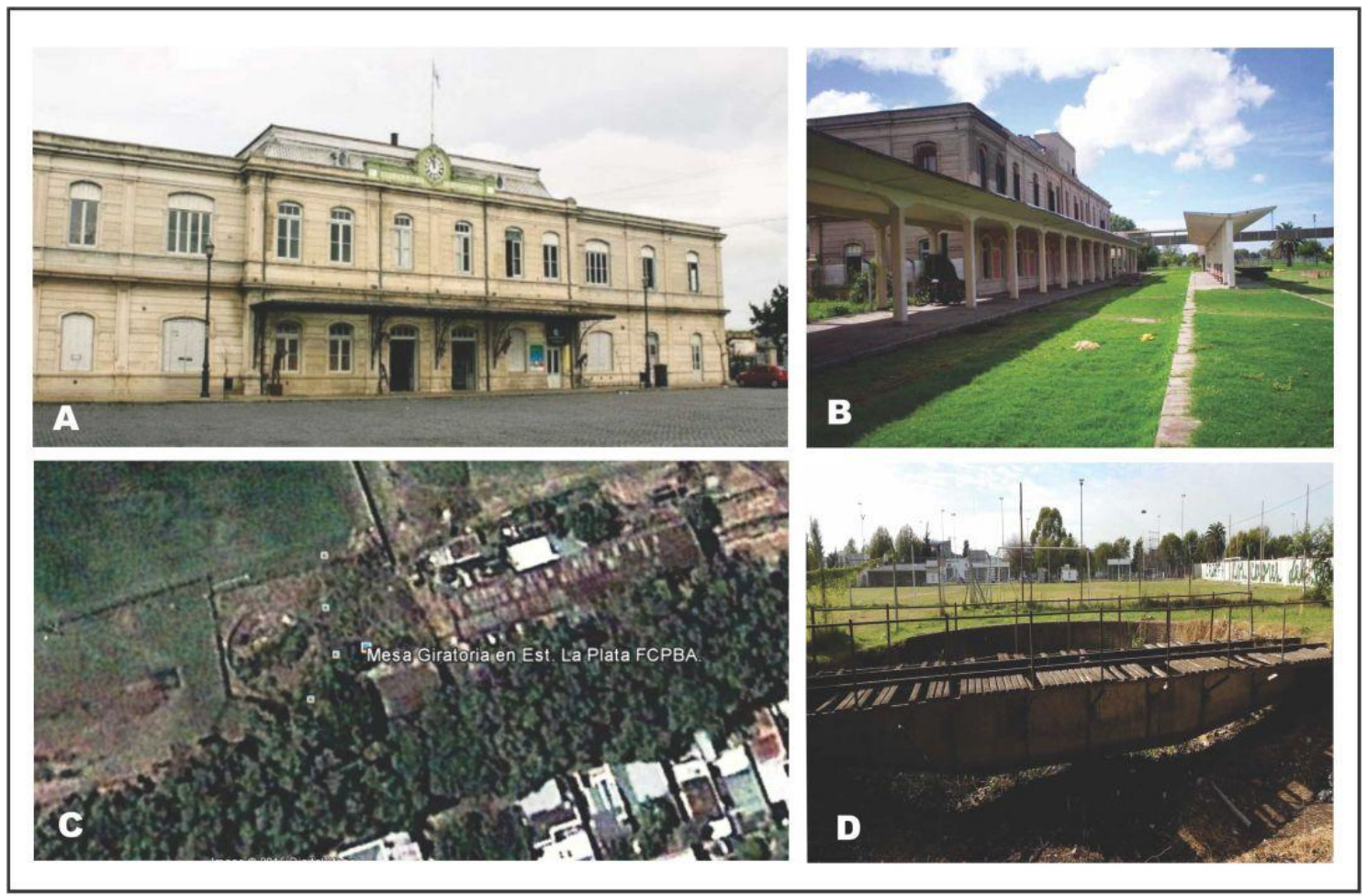

Figure 1: Actual photographs of La Plata Provincial Railway Station. Panel A: Front view of central station building. Panel B: Back view of central station building. Panel C: Aerial view for the location of locomotives turning table (34 $56^{\prime} 16^{\prime \prime} \mathrm{S}$ and $57^{\circ} 56^{\prime} 13^{\prime \prime} \mathrm{W}$ ) and Panel D: locomotive turntable status.
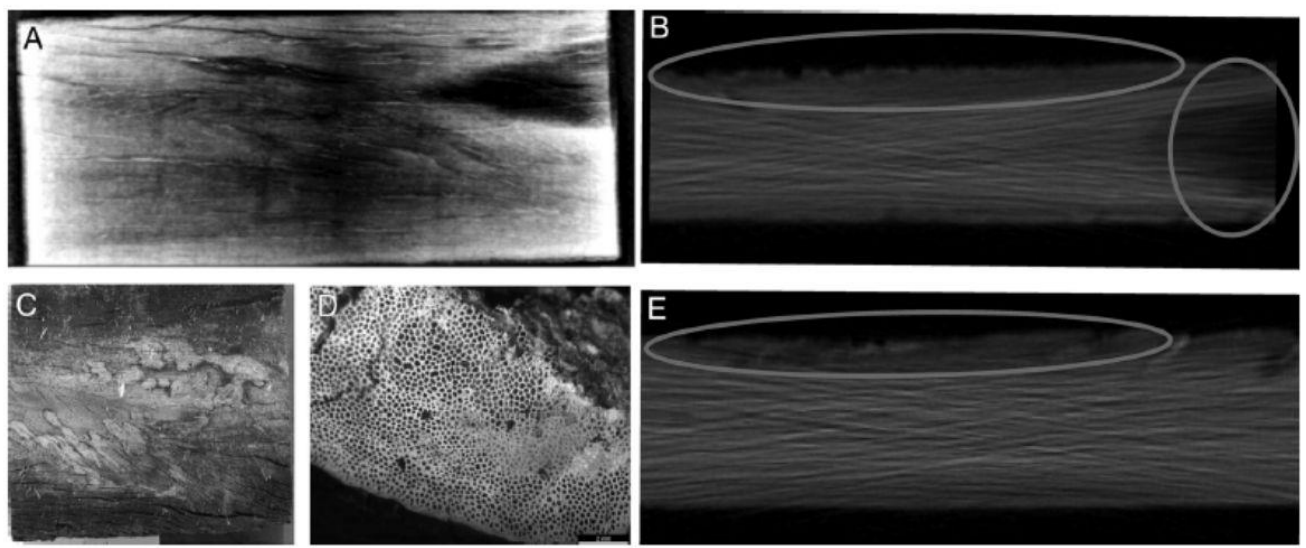

Figure 2: Locomotive turntable wood status. Panel A: X-ray images (RX) of deteriorated wood where the dark parts of the image represents loss of wood material agreeing with the presence of fungal hyphae. Panel B and E: Images from obtained by Computed tomography (CT) scan of deteriorated wood to analysed internal wood status; dark areas of the image are less dense due to loss of material and dark area of the image coincide with fungal mycelium presence. Panel C: Photograph of slats in an advanced status of deterioration caused by environmental and biological factors subjected to RX and CT. Panel D: Detail of basidioma. 

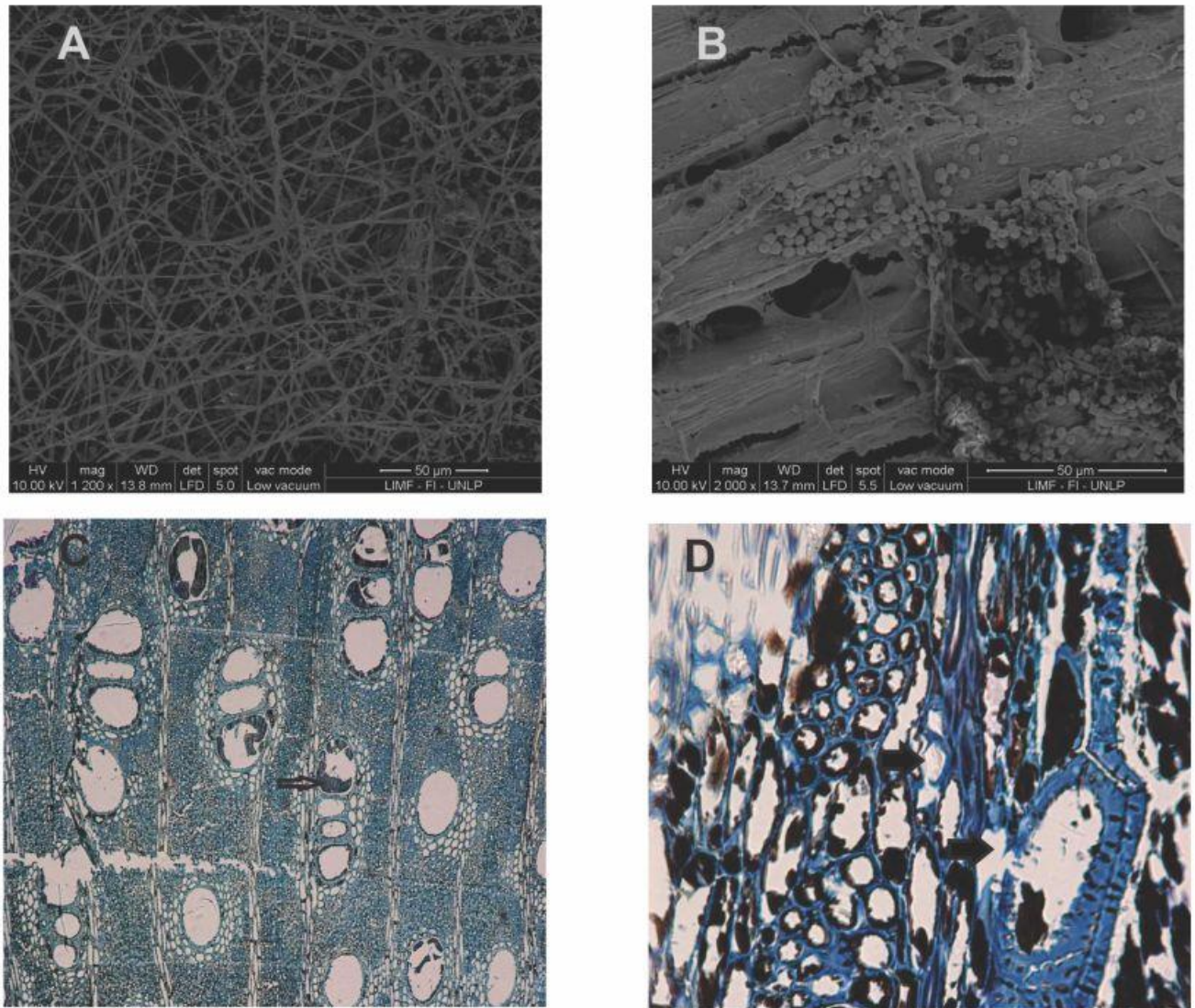

Figure 3: Microscopy of deteriorated wood samples. Panel A: scanning electron microscopy (SEM) images of ultra slim cut of dark area observed in RX and CT, dense presence of mycobiota hyphae. Panel B: SEM of ultra slim cut of grey zone where microstructure loss and the presence of spores were observed. Panel C: Optical microscopy (OM) images of dark area observed in RX and CT: altered wood appeared as compartmentalized by dark secretions deposited in axial/radial parenchyma and in vessel and cell lumina. Panel D: OM images where generalized cell wall erosion is evident (arrowheads), it was observed holes in vessel elements and erosion of wood cell walls.

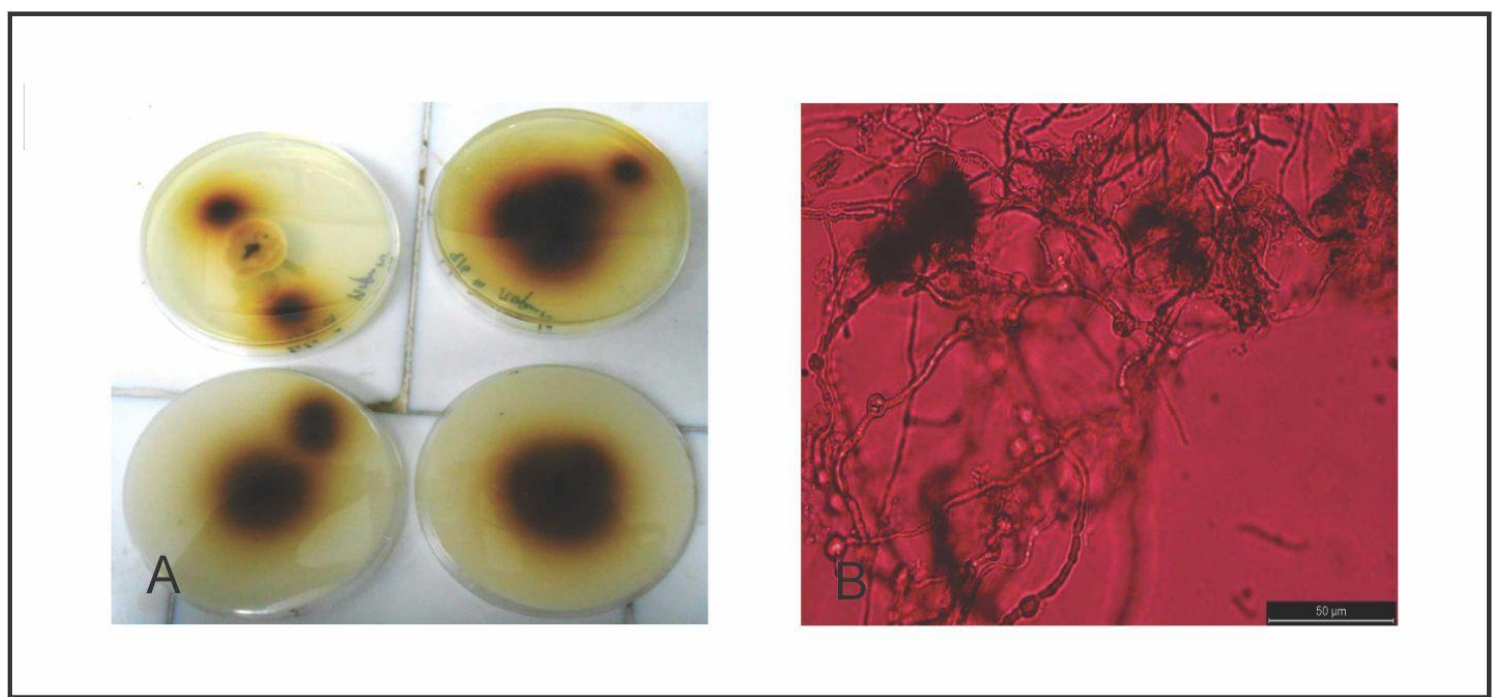

Figure 4: Panel A: Photographs of crops, brown halo shows oxidase activity (oxidation reaction of tannic and gallic acids). Panel B: Optical microscope photography of ultra-thin basidioma cutting.

\section{DISCUSSION}

Wood as organic material of cultural heritage is generally subject to the aggression of several heterotrophic microorganisms that use them as a source of nourishment. Many factors can contribute to biodeterioration, 
including the properties of the original materials, sources of nutrients, and the environmental conditions in which the objects are stored or exposed [20]. The evidence of biodeterioration is related to physical and chemical processes induced by microorganisms; they growth or penetration within the material with formation of micro-fractures, loss of cohesiveness, and disaggregation of the substrate and those are generally induced by physical damage [6]. This damage caused by microbial colonization is less extensive than chemical damage, which can arise when products of metabolic activity interact with the material, causing alteration of the substrate, which at times is irreversible and causes heritage materials loss. Biochemical deterioration induced by microbial colonization consists both in digestion processes, when microorganisms use the substrate as nourishment, especially when organic compounds are utilized, and in metabolic excretions, waste products, or other substances (e.g., organic and inorganic acids, pigments) [4].

This work was conclude that the fungal species was Phellinus chaquensis and that it would be the main responsible of the deterioration of the wooden slats, however, it has also been necessary the participation of atmospheric agents that contributed to deteriorate the material and to facilitate the colonization of fungi. Phellinus chaquensis has been proposed as the main agent responsible for the degradation of wood, showing that the degradation of this material, exposed to environment, is given by the coexistence of the action of micro and mycobiota together, besides the action of abiotic factors. This could be considered that happens as in natural ecosystems [7]. However, the complete understanding of biodeterioration processes is difficult, being the result of complex microbial interactions [21].

\section{CONCLUSIONS}

- This work shows the possibilities of some of the non-destructive testing that can be used for investigation of wooden historical structures.

- Wood in service exposed for several decades is affected by biotic and abiotic agents that are responsible for its deterioration.

- It is important to consider for this type of wood, chosen for its great mechanical resistance that, over time, the abiotic agents begin the process of deterioration: a) changes in the relative humidity of the material propitiates leaching and / or solubilization of the tannins b) UV radiation degrades lignin and cracks the surface of the material c) the wind and water factors generates cracks and gives off part of the external protection increasing the absorption of water by capillarity. All these processes favor the bioreactibility of the material, generating a microenvironment favorable for colonization by xylophagous fungi.

- It was concluded that deterioration analysis of images is a non-destructive alternative methodology, which allows measuring the structural condition of material. This is essential in heritage conservation because it allows defining correctly the deteriorated status useful to planning a conservation strategy, avoiding the asset loss.

A multidisciplinary approach is important when studying microbial impact on building materials. It is necessary to integrate concepts in order to determine the mechanisms of deterioration as well as the methods of control. Microbiologists, specialists in materials technology, chemists and restorers have to work together in order to avoid the use of protective treatments that can cause more damage to the building material than the microorganisms themselves. It is necessary to expand and extent knowledge in order to comprehensively approach the studies on the deterioration of wood heritage.

\section{ACKNOWLEDGMENTS}

To CICPBA (Comisión de Investigaciones Científicas de la Provincia de Buenos Aires) Directory Resolution No. 343/13 and 1085/14; for sponsorship for this research. To Paula V. Alfieri for her technical assistence.

\section{BIBLIOGRAPHY}

[1] NIEMZA, P., MANNES, D., "Non-destructive testing of wood and wood-based materials", Journal of Cultural Heritage, v. 13, 26-34, 2012.

[2] GAYLARDE, C., RIBAS SILVA, M., WARSCHEID, T., "Microbial Impacts on Building Materials: an overview", Materials and Structures, v.36, n. 5, pp. 342-352, 2003.

[3] GAYLARDE, C.C., MORTON, L.H.G., "Deteriogenics biofilms on buildings and their control: a review", Biofouling, v. 14, pp. 59-74, 1999.

[4] STRZELCZYK, A. B., "Observations on aesthetic and structural changes induced in Polish historic 
objects by microorganisms", International Biodeterioration and Biodegradation, v. 53, n. 3, pp.151-156, 2004.

[5] STERFLINGER K., PINZARI F., "The revenge of time: fungal deterioration of cultural heritage with particular reference to books, paper and parchment", Environmental Microbiology, v. 14, n. 3. Pp. 559-566, 2012.

[6] LÓPEZ-MIRAS, M., PIÑAR, G., ROMERO-NOGUERA, J., BOLIVAR-GALIANO, F.C., et al, "Microbial communities adhering to the obverse and reverse sides of an oil painting on canvas: identification and evaluation of their biodegradative potential", Aerobiologia, v.29, n. 2, pp. 301-314, 2013.

[7] STERFLINGER, K., "Fungi: Their role in deterioration of cultural heritage", Fungal Biology Reviews, v. 24, pp. 47-55, 2010.

[8] RAZÍM, V., MACEK, P., Investigation of historical buildings, Prague, NPÚ, 2011.

[9] HASNÍKOVÁ, H., KUKLÍK, P., "Non-destructive methods in the investigation of historical timber structure", Wood Research, v. 59, n. 3, pp. 411-420, 2014.

[10] LEHMANN, E. VONTOBEL, P., DESCHLER-ERB, E., et al, "Non-invasive studies of objects from cultural heritage”, Nuclear Instruments Methods, v. 542, pp. 68-75, 2005.

[11] TARTARINI J., Patrimonio ferroviario Bonaerense, Pasajeros al tren, Buenos Aires, Ed. Dirección Provincial de Patrimonio Cultural, 2009.

[12] URL: http://estacionprovincial.com.ar

[13] IACONIS, C., WRIGHT, J., "Studies on Basidiomycetes II. Systematic and biology of three species of Fomes”, Anales de la Sociedad Cientifica Argentina, v. 151, pp. 10-24, 1953.

[14] ROBLEDO G., URCELAY C., Wood fungi in native trees of the middle region of Argentina. Editorial Universitaria, Universidad Nacional de Córdoba, Argentina, 2009.

[15] TORTORELLI, L.A., Maderas argentinas. Buenos, Aires, Ed. Universidad de Buenos Aires, 1994.

[16] ROTH, I., GIMÉNEZ DE BOLSÓN, A.M., Argentine Chaco forests: dendrology, tree structure and economic use. 1. The semi-arid Chaco. Encyclopedia of plant anatomy, Berlin, Borntraeger, 1997.

[17] NOBLES, M.K., "Identification of cultures of Wood-inhabiting Hymenomycetes", Canadian Journal of Botany, v. 43, pp.1097-1139, 1965.

[18] BLANCHETTE, R., "Delignification by wood-decay fungi”, Annual Review Phytopathology, v. 29, pp. 381-398, 1991.

[19] HUNT, D., "Properties of wood in the conservation of historical wooden artefacts", Journal of Cultural Heritage, v. 13, n. 3, pp. 10-15, 2012.

[20] PAVLOGEORGATOS, G., "Environmental parameters in museums", Buildings Environmental, v. 38, n.12, pp. 1457-1462, 2003.

[21] MANDRIOLI, P., CANEVA, G., SABBIONI, C., Cultural heritage and aerobiology: methods and measurement techniques for biodeterioration monitoring, Netherlands, Springer, 2003. 